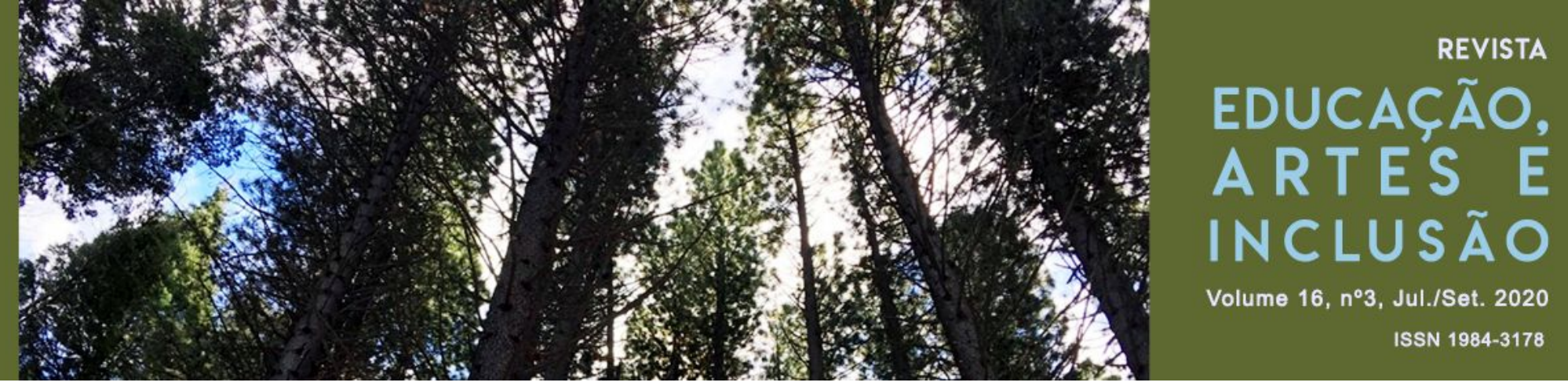

\title{
Práticas docentes no ensino de ciências e biologia para alunos com deficiência visual: uma análise à luz da perspectiva inclusiva
}

\section{Teaching practices in the teaching of sciences and biology for students with visual deficiency: an analysis in light of the inclusive perspective}

DOI: http://dx.doi.org/10.5965/198431781632020312

Louíze Roberta Mafra de Sousa

Universidade Federal do Maranhão

louize.mafra@gmail.com | ORCID

Carlos Erick Brito de Sousa

Universidade Federal do Maranhão

carloserickbrito@gmail.com | ORCID

\section{RESUMO}

O ensino de Ciências e Biologia para alunos com deficiência visual ainda enfrenta barreiras, como acesso à matrícula, profissionais especializados, materiais, métodos adaptados e tecnologias que auxiliem sua aprendizagem. Contudo, o olhar do professor com suas incertezas e dúvidas, sejam gerais ou específicas da disciplina, muitas vezes é negligenciado. Nesse contexto, a seguinte pesquisa objetivou analisar as práticas docentes de professores de Ciências e Biologia de uma escola de aplicação de uma universidade por meio da análise textual discursiva, considerando suas formações, dificuldades, concepções de inclusão e experiências. Observamos que a formação está intimamente ligada à prática docente, assim, o não estímulo à inclusão direciona como os docentes lidam com a diversidade em uma sala com alunos que possuam deficiência visual. Fatores da disciplina como a abstração/complexidade de seus conteúdos e a falta de formação adequada contribuem para a dificuldade em promover metodologias que alcancem os alunos. Para uma prática docente sensível às questões da diversidade, é fundamental uma formação inicial e continuada que considere a heterogeneidade e individualidade de cada aluno, materiais adaptados que estimulem outros sentidos além da visão, e o comprometimento dos docentes em buscar conhecimentos, saindo do modelo de educação estática ainda adotado por alguns profissionais.

Palavras-chave: Deficiência Visual. Educação Inclusiva. Formação Docente. Análise Textual Discursiva.

\section{ABSTRACT}

Science and Biology education for students with visual impairment still faces barriers, like access to school enrollment, specialized professionals, adapted materials and methods, and technologies that aid their learning. However, the teacher 's view with its uncertainties and doubts, whether general or specific of the disciplines, is often neglected. In this context, the following research aimed to analyze the teaching practices of Science and Biology teachers from a university application school, using Discursive Textual Analysis, whereas the 


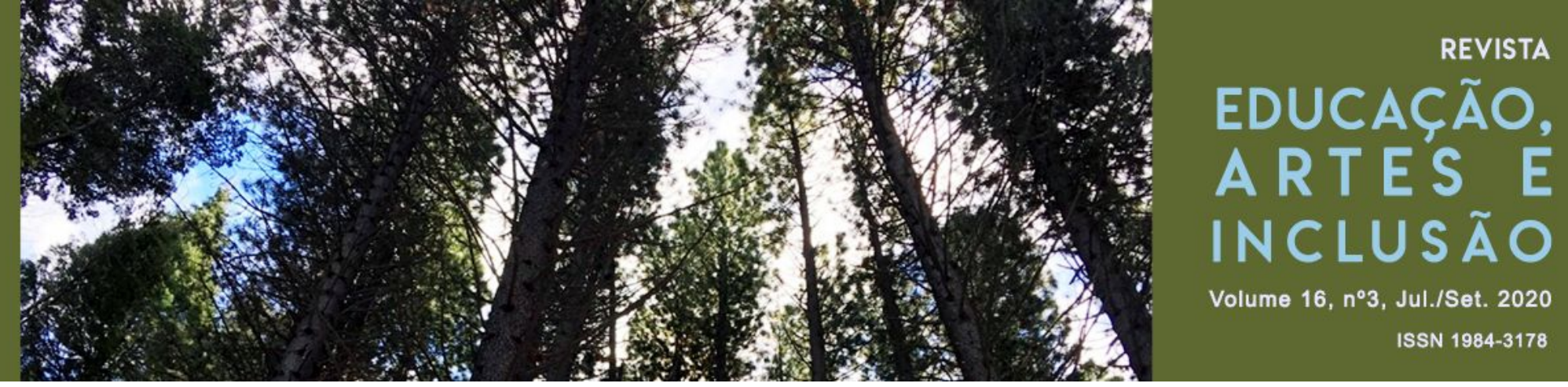

academic education, difficulties, conceptions of inclusion and experiences. We observed that the formation is closely linked to the teaching practice,thus, the non-inclusion stimulus directs how teachers deal with diversity in classes with students who are visually impaired. Discipline factors such as the abstraction/complexity of their contents and the lack of adequate training contribute to the difficulty in promoting methodologies that reach students. For a sensitive teaching practice for questions of diversity, it is fundamental an initial and continuous formation that considers the heterogeneity and individuality of each student, adapted materials that stimulate other senses beyond the vision for the teaching, and the commitment of the teachers to seek knowledge, leaving of the static education model still adopted by some professionals.

Keywords: Visual Impairment. Inclusive Education. Teacher Training. Discursive Textual Analysis.

\section{INTRODUÇÃO}

\subsection{EDUCAÇÃO INCLUSIVA E EDUCAÇÃO ESPECIAL}

A Inclusão pode ser considerada um tema gerador de muitas discussões, tendo em vista que, historicamente, os processos de construção das sociedades foram marcados pela exclusão de certos grupos sociais, dentre estes, as pessoas com deficiência. No tocante à exclusão educacional, não é fato recente que esse público teve seu direito à educação negligenciado durante bastante tempo. Diante desse cenário, é possível notar que as movimentações de luta em busca do acesso e permanência de alunos com necessidades educacionais especiais em instituições de ensino podem ser tidas como recentes, tendo ações mais veementes a partir da década de 1990.

Nesse ínterim, a Declaração de Salamanca, publicada em 1994, é considerada um marco para o movimento a favor da inclusão educacional, pois reforçou o discurso sobre a necessidade de pessoas com deficiência, transtornos globais de desenvolvimento e altas habilidades terem seus direitos educacionais assegurados (BRASIL, 1994). Com o fervilhar da luta pela inclusão educacional do público-alvo da Educação Especial, as esferas governamentais se viram obrigadas a reformular suas políticas de educação, e, assim, fornecer serviços e recursos necessários para a educação de alunos com deficiência. 


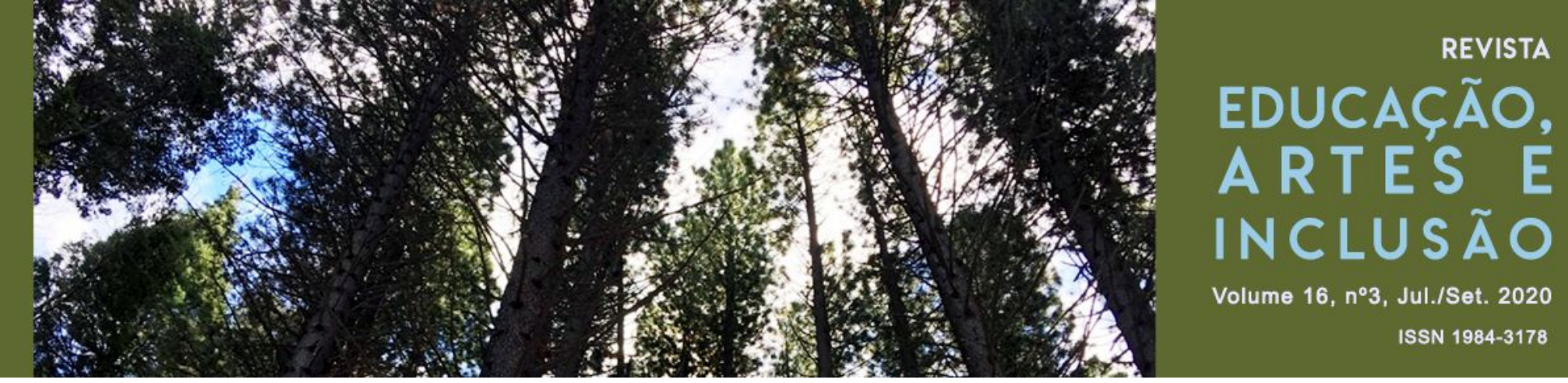

Porém, nem mesmo toda a "[...] boa vontade dos professores e preparação são condições suficientes para garantir uma escola inclusiva" (TOLEDO; MARTINS, 2009 , p. 3). Assim, é preciso suprir a necessidade de formação docente inicial e continuada, em que seja trabalhado o respeito à diversidade, para uma futura prática docente de qualidade, com a valorização das peculiaridades de cada aluno e da inclusão (JESUS; EFFGEN, 2012).

Neste contexto o presente estudo tem como objetivo geral: Analisar as práticas docentes de professores de Ciências e Biologia em relação aos alunos com deficiência visual do Colégio Universitário (Colun), escola de aplicação da Universidade Federal do Maranhão (UFMA). E como objetivos específicos: Analisar as metodologias empregadas pela escola e professores de Ciências e Biologia em aulas para turmas que possuem alunos com deficiência visual; Verificar as possíveis dificuldades encontradas por estes professores no para alunos com deficiência visual; Identificar as concepções sobre Educação Inclusiva dos docentes pesquisados; Investigar as relações existentes entre as práticas docentes e as formações acadêmicas destes professores.

\section{METODOLOGIA}

O trabalho possui abordagem qualitativa, na qual os procedimentos adotados permitem ao pesquisador um contato mais íntimo com seu objeto de pesquisa. Assim, os processos passam a ter mais valor para a construção das inferências e interpretações sobre o fenômeno do que propriamente o resultado (BOGDAN; BIKLEN, 1994). Trata-se de uma pesquisa do tipo estudo de caso, cuja intenção é investigar de maneira profunda um fenômeno, porém limitando esse fenômeno a uma determinada condição (YIN, 2001).

O Colun, escola de aplicação da UFMA, foi criado em 1968, visando a contribuir na preparação de candidatos para ingressar no ensino superior e oferecer aos alunos do antigo $2^{\circ}$ grau um ensino diversificado. Após reformas em seu 


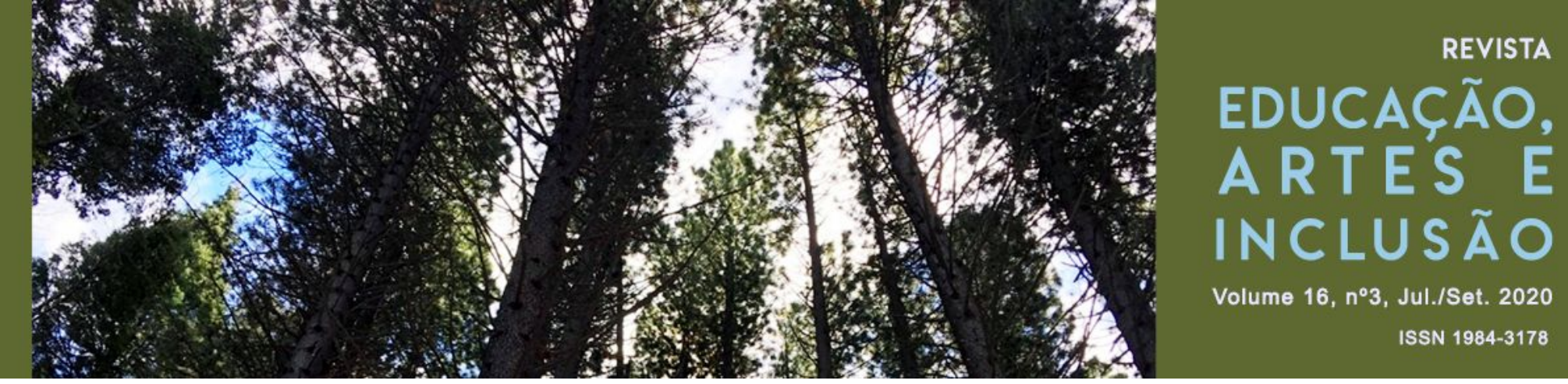

\section{RESULTADOS E DISCUSSÕES}

Os resultados e discussões da pesquisa são apresentados em quatro metatextos, os quais trazem as interpretações feitas a partir das diferentes categorias construídas no processo de análise. Foram entrevistados sete sujeitos, para os quais foram adotados códigos, compostos por inicial remetendo à sua função na escola, acompanhado de número quando necessário, visando à manutenção do sigilo sob suas identidades. Sendo estes, cinco professores de Ciências e Biologia (P1 a P5), um profissional da coordenação pedagógica (CP) e um do Napnee (N).

É importante ressaltar que os participantes, em sua maioria, trabalham na instituição há mais de uma década ou duas como no caso de $\mathrm{P} 1$, docente do Colégio Universitário há 24 anos. Sendo assim, as informações presentes em seus relatos nos revelam as perspectivas de profissionais que possuem longo contato ministrando aulas para turmas com alunos público alvo da educação especial.

\subsection{ESTRATÉGIAS E RECURSOS}

Como fundamentação para a criação da categoria Estratégias e Recursos, foram utilizados documentos oficiais, como a Política Nacional de Educação Especial na Perspectiva da Educação Inclusiva (BRASIL, 2008) e as Diretrizes Nacionais para a Educação Especial na Educação Básica (BRASIL, 2001a). Estes documentos trazem, em seus textos, serviços e estratégias para a garantia da entrada e permanência do aluno com deficiência em instituições de ensino, a exemplo da presença de profissionais especializados em Educação Especial/Educação Inclusiva, materiais didáticos adaptados, promoção de cursos de formação voltados aos educadores e etc.

Os mecanismos utilizados pelo Colun para a promoção do ensino inclusivo seguem o que é exigido por lei, por meio de estratégias que visam garantir o acesso e permanência do aluno com deficiência na instituição, com a presença do Napnee, 


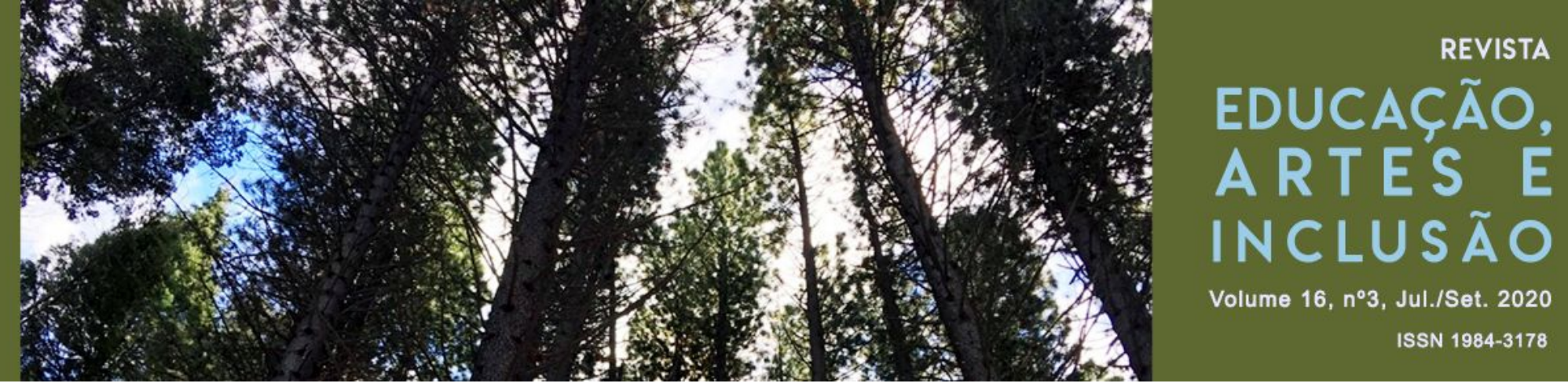

Quando indagado sobre a participação dos professores e gestores no processo inclusivo no Colun, a entrevistada CP comenta:

A gente tem um grupo de professores muito bons, mas nós temos também professores que ainda não aceitam essa condição. O não aceitar não significa que ele não aceita aquele aluno na sala de aula. O não aceitar é no sentido que ele desenvolve o trabalho dele fazendo de conta que ele não tem aquele aluno (...) ele acaba excluindo porque trata o aluno como se ele fosse um aluno, dito, considerado normal.

Além da Coordenação Pedagógica, os próprios docentes confidenciaram que de fato, ainda há resistência por uma minoria do corpo docente em ministrar aulas para alunos com deficiência visual. P3 expõe: “[...] trouxe uma nova visão, para alguns professores, é claro. Tem muito professor que ainda é muito reticente em relação a isso, tem professor que diz: Ah! Se tiver alguma turma com deficiência, eu não vou trabalhar, porque eu não sei”. A esse respeito, Mantoan (2003, p. 41) afirma que: "A maioria dos professores tem uma visão funcional do ensino e tudo o que ameaça romper o esquema de trabalho prático que aprenderam a aplicar em suas salas de aula é inicialmente rejeitado". Ou seja, muitos professores ainda veem o ensino como algo estático e sem flexibilidade, onde a zona de conforto criada por eles deve ser respeitada e mantida.

Algo bastante citado pelos professores quando perguntados acerca de modelos e materiais didáticos, foi o notebook, que é oferecido aos alunos com deficiência visual para o acompanhamento das aulas, a realização de atividades, leitura do livro didático na versão digitalizada, e como isso auxiliava no processo de ensino e aprendizagem. No ensino de Ciências e Biologia para alunos com deficiência visual, o notebook como um auxílio nesse processo é considerado uma tecnologia assistiva, que se caracteriza a partir do uso de maquinário e tecnologias da informação e comunicação, buscando a equidade e qualidade para seus usuários (CARVALHO, 2014). 


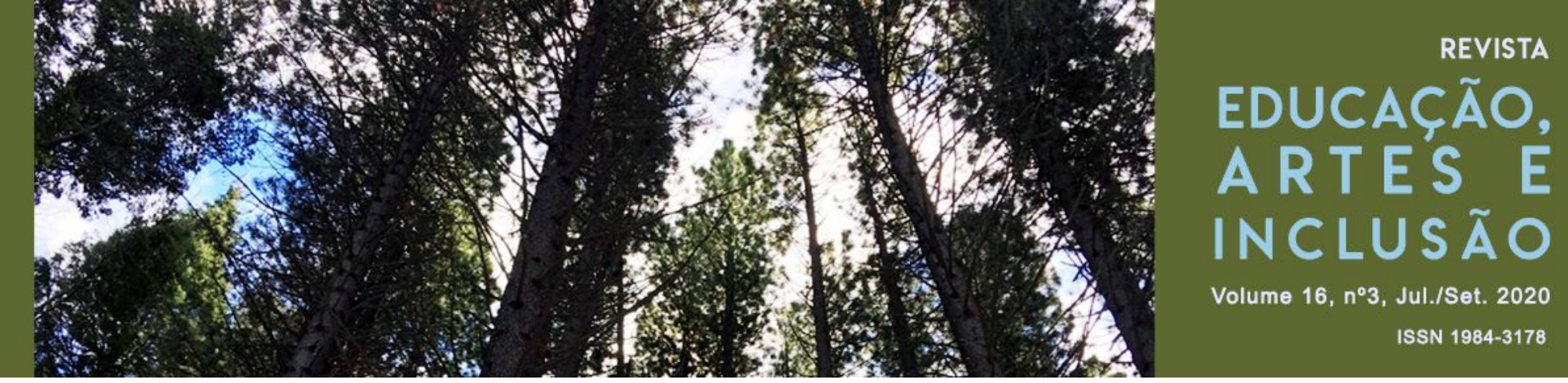

O uso dessa tecnologia em sala de aula aparentemente facilita o trabalho do professor, visto que foi evidente a satisfação dos mesmos quando falavam sobre o notebook. P4 reforça: "Aqui melhorou bastante, porque inclusive o material do aluno né, o livro já tem lá no leitor digital deles. Então tem acesso ao livro lá pelo computador né ... Confesso que eu nunca ... não sei nem como é que funciona aquilo".

No que concerne ao uso das tecnologias no processo inclusivo, a Secretaria Especial dos Direitos Humanos (BRASIL, 2009) realizou uma pesquisa em que afirma que muitos professores e gestores, quando investigados, são insistentes em citar os benefícios dessa utilização, no entanto, demonstram desconhecimento quanto ao uso dos recursos presentes nas escolas em que trabalham. O termo Tecnologia Assistiva, não foi utilizado pelos docentes durante as entrevistas, porém, todos asseveraram que as tecnologias auxiliam no ensino. A literatura reitera que a utilização de recursos de informática aliados à tecnologia assistiva pode promover maior agilidade na aquisição da linguagem, bem como mobilizar a interação em sala de aula entre professor e aluno, se utilizado e conhecido pelo docente de maneira efetiva.

A inquietação gerada nesse ponto, advém do fato de os docentes terem acesso à informação e orientação, afirmarem ser a favor do uso das tecnologias em sala como recursos no ensino inclusivo, contudo, não se permitirem ir além da superfície. É possível perceber que, além de reconhecer a melhoria no ensino por meio das tecnologias criadas/adaptadas a favor do aluno com deficiência, os educadores precisam conhecer seu funcionamento, o que pode thes garantir maior propriedade ao exercitar sua função. Dessa forma, podem corroborar ao ensino inclusivo, tentando melhorá-lo, discutindo e adaptando o material de acordo com a necessidade de seus alunos, ajudando-os a se apropriarem desses recursos (SEEGGER; CANES; GARCIA, 2012). 


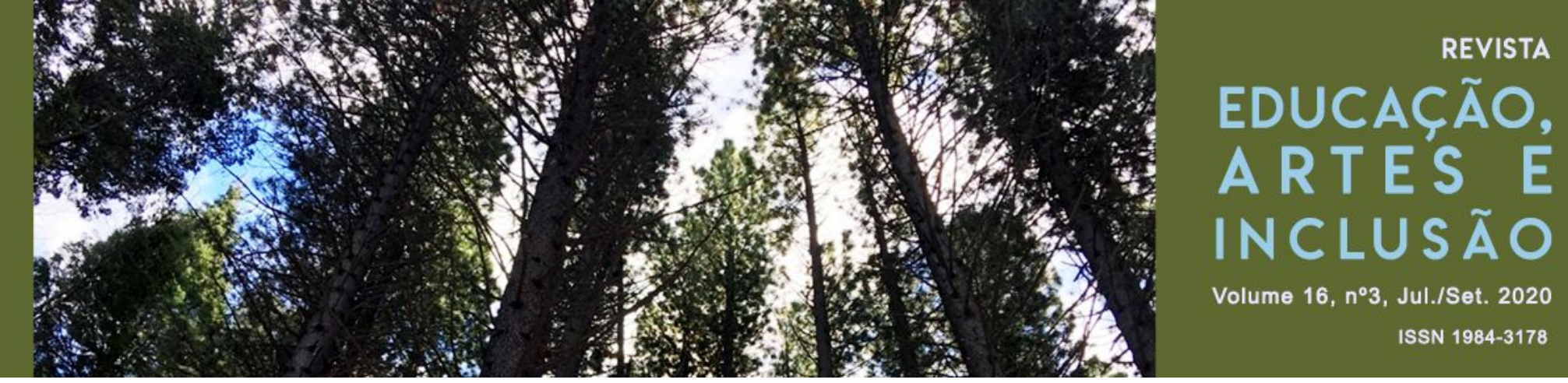

Durante a pesquisa, a partir dos discursos apresentados pelos professores do Colun, foi possível constatar que fazem uso de recursos para o ensino de Ciências e Biologia a alunos com deficiência visual, a exemplo de computadores, confecção de materiais, tradução de textos para o Braille, acompanhamento no contraturno com aulas sobre linguagens (Braille) e reforço de alguns conteúdos. Todavia, ainda que se ofereçam materiais, cursos e palestras, a orientação e ajuda do Napnee na elaboração de materiais, muitos professores ainda se sentem perdidos quanto a presença de alunos com deficiência visual em suas turmas, o que causa dúvidas e inseguranças. Estas dificuldades podem, por vezes, vir a comprometer a implementação de um ensino inclusivo, que valorize potencialidades de cada aluno e incentive à autonomia.

\subsection{DIFICULDADES DA PRÁTICA DOCENTE}

Essa grande categoria foi dividida em 3 subcategorias: Desafios pessoais, que trata das dificuldades, incertezas e conflitos dos sujeitos enquanto professores de uma turma que possui alunos com deficiência visual; Desafios em sala, sobre os desafios enfrentados por estes professores em termos de metodologias e de que maneira isso pode influenciar no processo de ensino e aprendizagem; e Conteúdos Específicos, que desvela as dificuldades específicas no ensino de Ciências e Biologia para alunos com deficiência visual e a percepção dos docentes a respeito de como isso afeta a aprendizagem da turma em geral.

O ensino para alunos com deficiência tem sido carregado ao longo dos anos por um peso que o estigmatiza e estereotipa como algo difícil de ser realizado, onde deve haver esforço dobrado para que sejam alcançados "resultados positivos". Essa visão tem se enraizado em alguns setores responsáveis por propostas de educação inclusiva, devido a intensificação desse processo e de seus desafios nos últimos anos (MANTOAN, 2003). 


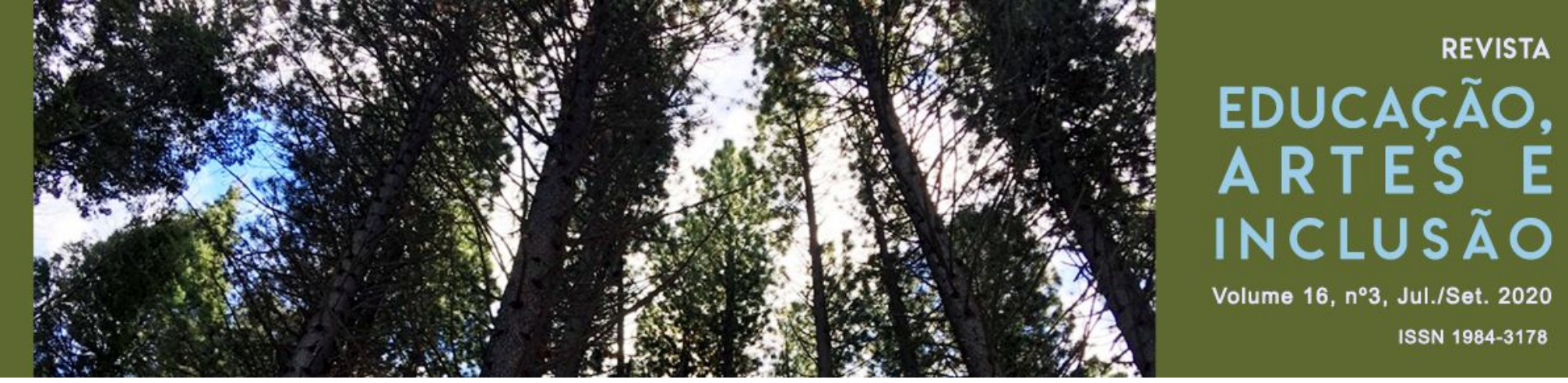

perceptível o reconhecimento dos limites dos próprios alunos dentro desse processo, como o relacionamento da turma, além de estarem sendo apresentados a conteúdos na sala de aula, alguns ainda estão se familiarizando com o uso das tecnologias e o ensino de linguagens. A respeito destes tipos de situações, Castro (2009) argumenta que o professor, além de estar atento à turma como um ser coletivo, também deve prestar atenção à individualidade de cada aluno durante o processo de ensino e aprendizagem.

Nos momentos em que se perguntou sobre que tipos de modificações na metodologia eram feitas em turmas com alunos com deficiência visual, houve um consenso entre os professores em dizer que o ritmo das aulas deveria ser mais lento.

Não pode ter aquela aula corrida (P2).

Tem que dar uma atenção especial (...) tornar a aula mais lenta (P4).

A justificativa dos professores é que o conteúdo deve ser ministrado de maneira mais lenta, pois os alunos com deficiência visual demandariam atenção, e, por muitas vezes, não conseguiriam "acompanhar" o ritmo da turma e compreender o que é dito, em função de parte dos conteúdos de Ciências e Biologia serem considerados abstratos pelos professores.

Teodoro (2014) elenca alguns conteúdos que são considerados abstratos, e que geralmente necessitam de auxílio visual de Ciências e Biologia, sendo eles: Evolução, Genética, Cadeia Alimentar, Célula, Fisiologia, Planetas, dentre outros. Nas entrevistas, dois temas foram os mais citados entre os professores como "os mais difíceis" de serem ministrados. P3 e P4 citam Genética como o conteúdo mais abstrato para se lecionar:

Em Genética, eu tive muito trabalho (...) Foi meio complicado (...) leva em consideração aspectos de cálculo (P3).

Peguei no terceiro ano, Genética, pior ainda, não é palpável (P4). 


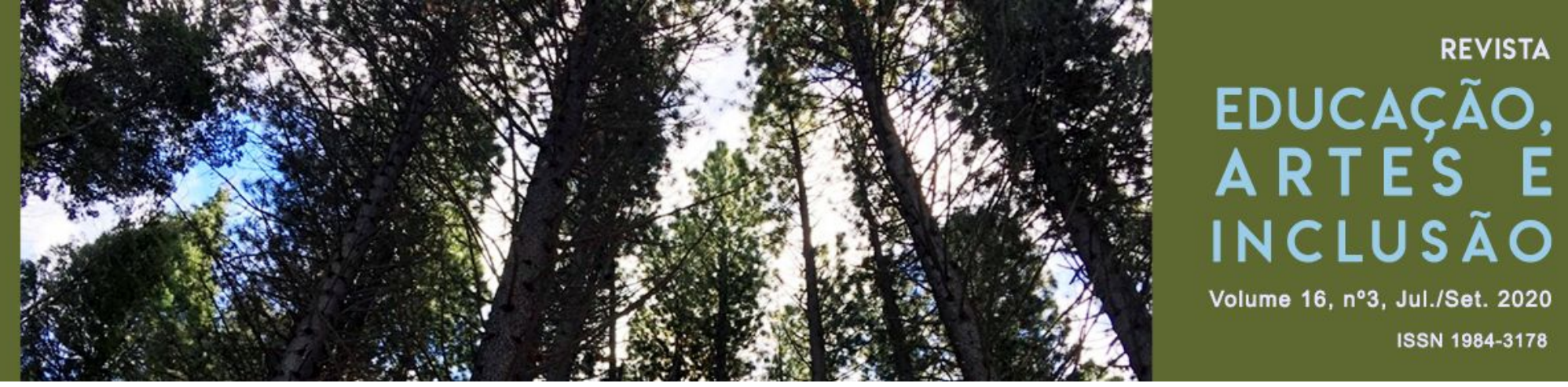

(...) tem que chamar atenção (...) Atrapalham a audição do aluno, ele tem um certo entrave (...) a turma, não vejo ela contribuir muito com ele, nenhum momento tu vê em volta dele, ou do lado, sempre afastada (P5).

Já P2 e P3, ao dividirem suas experiências passadas, concordaram ao dizer que, em suas turmas anteriores, o relacionamento dos alunos que possuíam deficiência visual com o resto da turma era muito bom, e que o auxílio e a troca de informações eram frequentes.

Mesmo tratando-se de experiências diferentes, é perceptível como o relacionamento entre os discentes influencia na maneira como os alunos com deficiência seguiram durante sua experiência escolar, em como isso reflete não apenas na tentativa de inclusão, mas também no processo de ensino e aprendizagem. Costa (2011), quando trata sobre o papel da afetividade no contexto escolar, explica que a afetividade é imprescindível para a construção da autoestima, confiança e um estímulo para o processo educacional.

Podemos observar que existem diversas dificuldades enfrentadas pelos docentes no processo inclusivo, relacionadas estritamente à sala de aula ou a desafios de cunho mais pessoal e experiencial. Grande parte dos docentes confessou possuir essas dificuldades, por não se sentirem preparados para lidar com alunos com deficiência, devido à sua formação inicial não ter dado a oportunidade de experienciar essas situações. "[...] De maneira geral, as licenciaturas não estão preparadas para desempenhar a função de formar professores que saibam lidar com a heterogeneidade posta pela inclusão" (PLETSCH, 2009, p. 150).

Todos os entrevistados possuem mais de 10 anos desde a finalização de sua graduação, ao passo que a disciplina de Educação Especial nos currículos das licenciaturas foi proposta pelo Conselho Nacional de Educação pela primeira vez nas Diretrizes Nacionais para a Educação Especial na Educação Básica em 2001. Contudo, antes mesmo dessa data, a Lei 9.394 de 20 de Novembro de 1996 já 


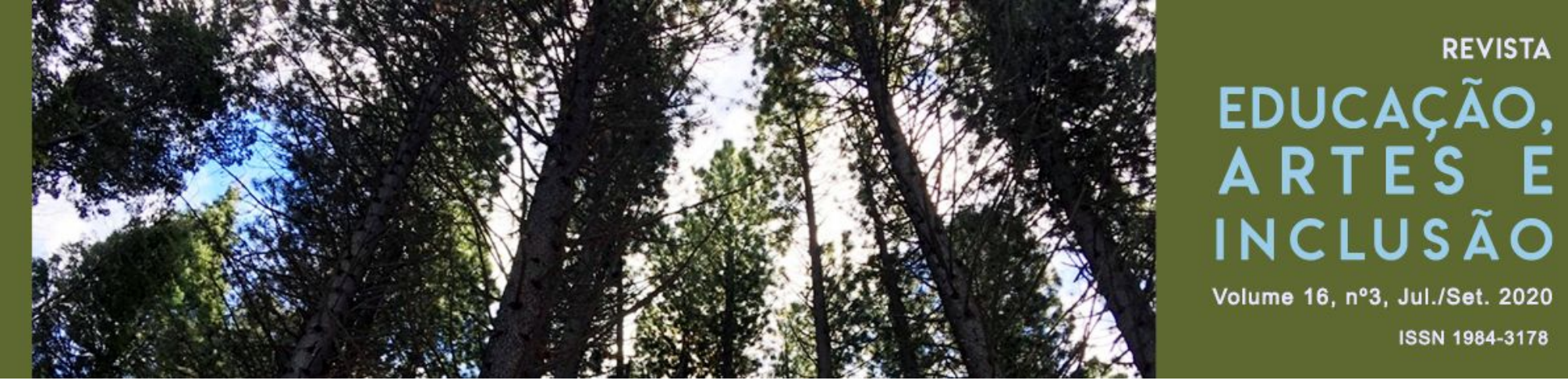

\subsection{CONCEPÇÕES DOS PROFESSORES E GESTORES SOBRE INCLUSÃO}

A construção deste metatexto teve suas subcategorias fundamentadas a partir do trabalho de Sant'Ana (2005), intitulado Educação Inclusiva: concepções de professores e diretores. Durante a etapa de definição das unidades de significado, foram encontradas semelhanças com a proposta desta autora, que possuía categorias como: Compartilhar espaço físico; Integração na sociedade; Crianças com deficiência; Participação de todos e Direito à educação. No presente trabalho, utilizamos como categoria geral: Concepções de inclusão, e como subcategorias: Compartilhar o espaço físico; Interação; Efeitos do ensino inclusivo; Ação docente.

Durante as entrevistas, identificamos diversas concepções sobre inclusão, as quais partem desde ideias consideradas simplórias, como o fato de estar no mesmo espaço, até as que agregam questões econômicas, sociais e pedagógicas. De acordo com Sant'Ana (2005), as concepções sobre Inclusão para grande parte dos docentes e gestores têm se resumido à matrícula e ao compartilhamento do mesmo espaço físico da escola.

Nas concepções de inclusão identificadas na pesquisa, conseguimos observar que nenhum dos professores se enquadrou em apenas uma delas, todos demonstraram ter visões amplas sobre inclusão, citaram o espaço físico como importante, entretanto, outros pontos foram levantados, como a interação entre os alunos e as turmas, a relação família-escola, como importante para a contribuição no trabalho mútuo, e a formação de professores como essencial ao ensino inclusivo.

Quando questionados acerca do que seria um ensino inclusivo, dois professores citaram o compartilhamento do espaço físico como essencial.

Devemos trazer essas pessoas para o convívio da escola (P1).

Eles têm que estudar mesmo é na sala, só com uma ajudazinha (P2). 


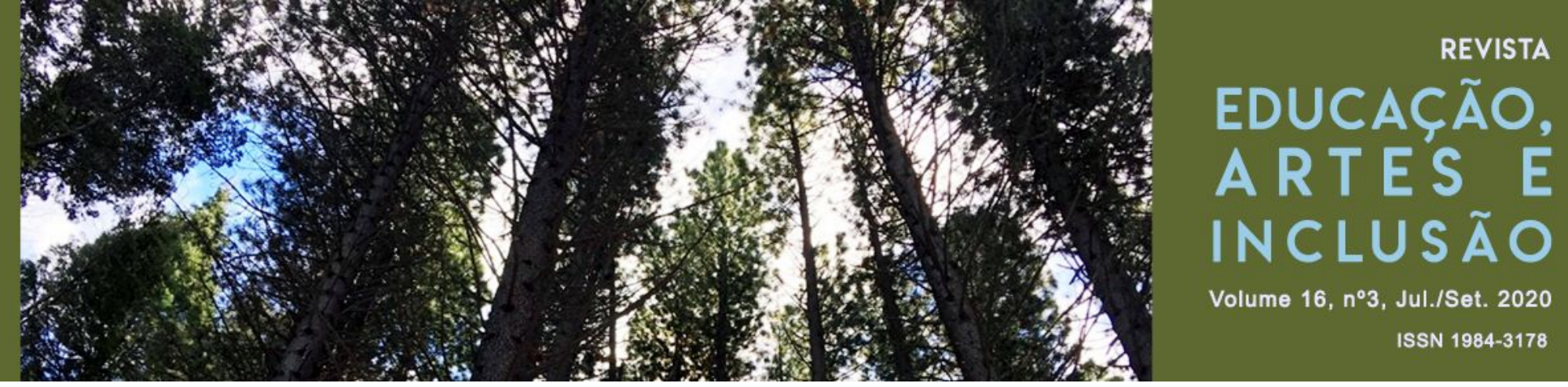

auxiliar no processo inclusivo: "A turma também precisa ser trabalhada (...) acompanhar o trabalho".

No que diz respeito à participação da comunidade escolar, a família também tem um papel importante no Ensino Inclusivo. CP explana que, no Colun, as famílias são convidadas a participar dos momentos de discussão, chamadas a contribuir com informações sobre os alunos, e orientadas a respeito de ações que devem ser trabalhadas no âmbito familiar para o desenvolvimento da autonomia:

Então, aí as famílias elas são chamadas né, pra poder participar desse processo e existe todo um trabalho que é feito com elas também. O Napnee, que é o núcleo de assistência desse alunos, que desenvolve um trabalho de acompanhamento desses alunos, também trabalha com as famílias. E elas têm comparecido, elas trazem as suas contribuições (CP).

Entretanto, o nível de participação da família atualmente ainda não é o almejado pela instituição. Alguns fatores como a superproteção de alguns responsáveis, e, em alguns casos, a negação da deficiência dos filhos podem influenciar de maneira negativa o trabalho executado pelos profissionais do Colun. Sobre isso, CP tece uma crítica:

[...] mas ainda é muito limitado, até porque, na maioria das vezes, as famílias também não sabem como agir, o que fazer. Então, elas contribuem dentro daquilo que elas têm condições de contribuir (...) Nós temos um aluno, que quando ele chegou na escola, ele era um aluno muito dependente, ele não tinha autonomia por ter deficiência visual. E essa dependência era exatamente porque a família mesmo não tratava de trabalhar essa autonomia. Então, a família numa superproteção, acaba prejudicando, mas é uma condição que a gente pode dizer, assim, que é até natural, porque a mãe, o pai querem proteger o seu filho, porque sabem que ele tem uma deficiência, e isso é lógico que atrapalha o processo.

Conforme Rego (1995 apud SILVA, 2015), a inclusão é um processo sociointeracionista que tem como um dos protagonistas a relação família-escola. Nessa relação, ambos podem contribuir ou dificultar o processo, mesmo que 


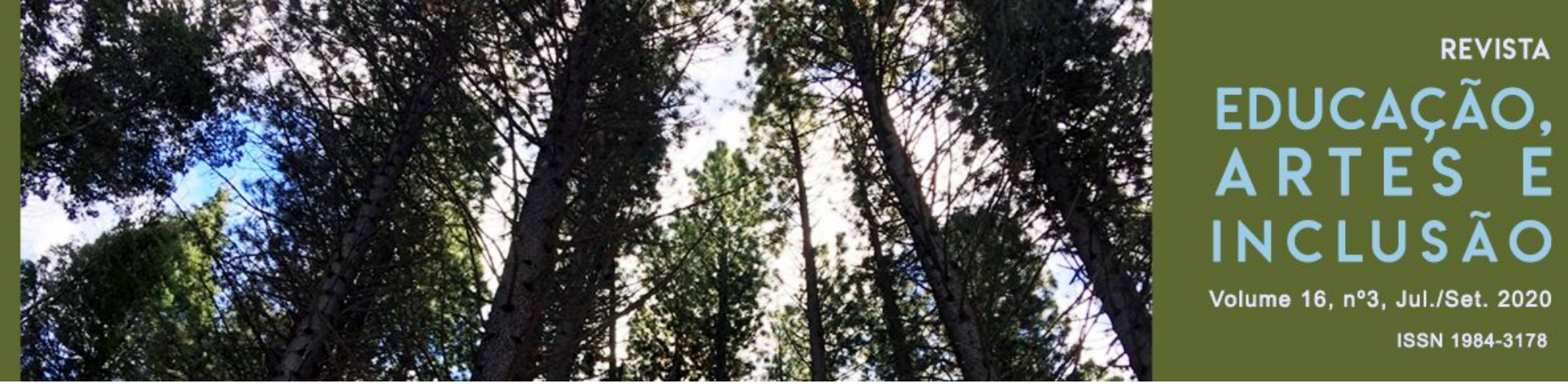

deficiência em instituições de ensino regular, porém, argumenta que isso só pode ser feito a partir da oferta de um suporte adequado, e especifica a formação dos professores.

Agora com certeza é aquela questão, é a preocupação da escola colocar e ter todo o aparato pra fazer com que o aluno se sinta bem. "Ah! A escola oferece educação inclusiva, mas não prepara os profissionais" (P4).

Em virtude dos comentários a respeito da preparação dos docentes do Colégio Universitário, foram feitos questionamentos ao professor entrevistado que relatou já ter trabalhado em outras instituições. Entretanto, a experiência de ter alunos com deficiência visual ocorreu apenas no Colun, portanto, quando houve a cobrança do ensino inclusivo na instituição, o mesmo não se sentia e ainda não se sente preparado para ministrar aulas para alunos com deficiência visual.

Inspirados pelos trabalhos do pesquisador canadense Maurice Tardif, Braun e Marin (2012) alertam que as práticas docentes estão sempre atreladas aos saberes docentes, que são constituídos de saberes profissionais, saberes das disciplinas, saberes curriculares e saberes da experiência. Enquanto a formação docente, que abarca os saberes curriculares, das disciplinas e da experiência, não proporcionar aos formandos um ensino que valorize a diferença, a heterogeneidade dos alunos e o fortalecimento da busca pelas potencialidades de cada um, as práticas docentes futuras serão limitadas e ineficientes na tentativa de contribuir para um ensino inclusivo.

\subsection{FORMAÇÃO E PRÁTICA DOCENTE}

A partir dos dados obtidos, emergiram as seguintes categorias: Formação Inicial, na qual são destacadas unidades de significado de momentos, situações e experiências relacionadas à graduação; e Prática Docente, em que observamos as 


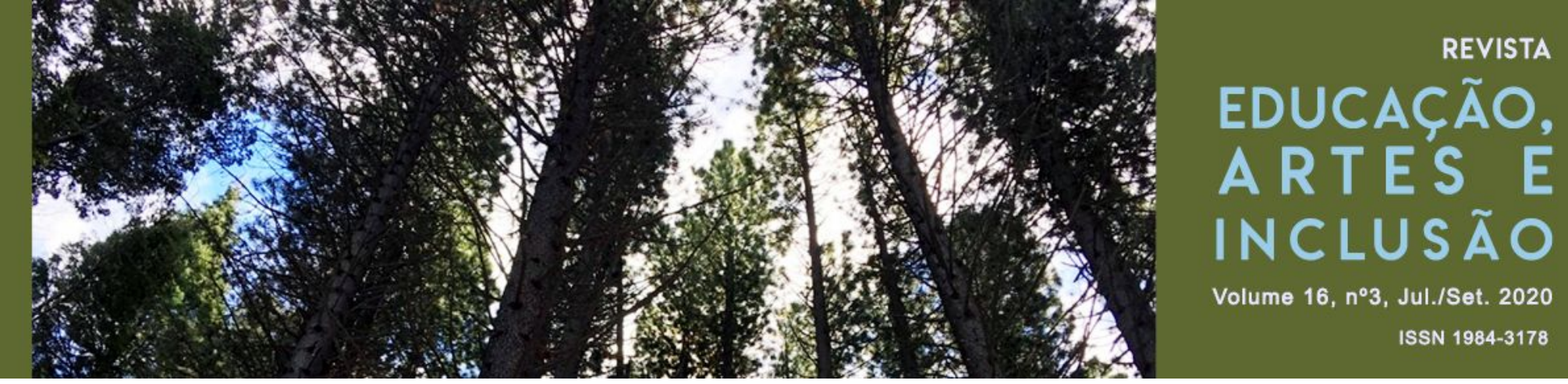

reverberações da falta de algumas vivências durante a formação inicial na atual prática docente dos professores.

A carência de momentos relacionados à Educação Especial/Inclusiva na formação inicial dos educadores entrevistados e as consequências profissionais disso foram os pontos mais citados pelos docentes. Quando indagado sobre as consequências da falta desses momentos, P3 explana que sua prática foi prejudicada, pois ele e seus colegas iniciaram sua vida na docência sem base alguma: "Prejudicou porque, não só eu, como todos os professores que trabalham aqui e que fizeram graduação com licenciatura (...) dentro dos nossos cursos específicos, nós não tivemos, nós chegamos com embasamento nenhum".

Essa fala nos ajudou a compreender que certas visões limitadas para a heterogeneidade e especificidades em sala podem ser resultados da ausência de momentos voltados à inclusão na graduação desses professores. No entanto, apesar das dificuldades geradas pela falta de um espaço durante a graduação voltado à inclusão, algo muito destacado pelos mesmos foi o trabalho do Colun em tentar promover um ensino inclusivo, e como os frutos desse processo têm envolvido não apenas os alunos, mas também contribuído para a desmistificação de concepções equivocadas sobre o que seria um ensino inclusivo entre os professores.

A experiência do trabalho em sala de aula e o suporte dado pela gestão e pelos profissionais do Napnee podem ser considerados de extrema relevância para a construção de uma nova visão por esses educadores, nas quais as especificidades de alunos com deficiência visual têm o papel de contribuir para a construção de novas metodologias e posturas por parte dos docentes.

De acordo com Tricolli (2002 apud DUEK, 2007, p. 5), "[...] para que um professor possa oferecer uma boa formação para seus alunos, ele precisa estar também bem formado". Nesse sentido, Tricolli se refere à qualificação dos educadores, tendo condições adequadas de ensino, experiências que os permitam 


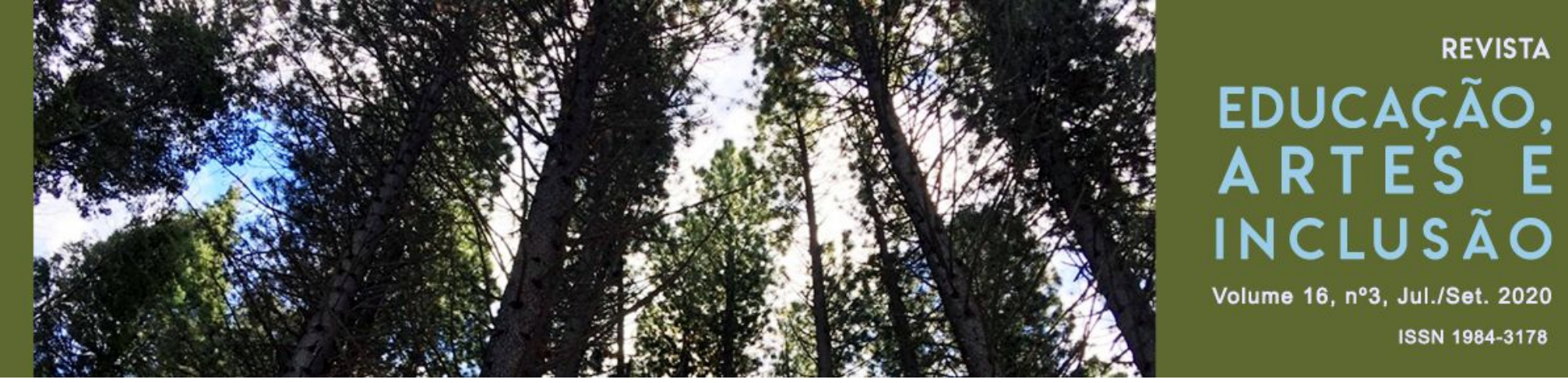

vivenciar parte da licenciatura durante a vida acadêmica, bem como uma carga teórica e prática que valorize a inclusão. Mas se a prática docente está intimamente atrelada à formação inicial, como promover e praticar a inclusão se não houver estímulo durante esta etapa da formação?

A ausência de uma disciplina destinada à Educação Especial//nclusiva durante a formação inicial foi uma das situações identificadas pelos docentes entrevistados como fator importante para suas práticas docentes. Vejamos algumas falas a respeito dessa questão:

Não, nunca tive nada (P2).

Na época que eu fiz a graduação não tinha isso (P4).

Por serem os profissionais que passam a maior parte do tempo em contato com os alunos e tendo a oportunidade de vivenciar o seu dia a dia, o professor deve ser considerado peça importante na construção de um ensino inclusivo. Portanto, quando nos atentamos às suas experiências (teórica e prática) durante a formação inicial, devemos lembrar que constituirão uma base relevante, servindo como referência para a apresentação de novos saberes em uma prática docente inclusiva.

Outro ponto relacionado à falta de uma disciplina destinada à Educação Especial/Inclusiva na graduação é o despreparo citado pelos docentes. Muitos se consideram incapazes e inseguros quanto ao desenvolvimento de metodologias e estratégias. Alves (2012) ressalta que haverá momentos em que os professores vivenciarão situações conflitantes, e o alicerce para o confronto dessas situações pode ser dividido em três pilares: boa formação inicial, formação continuada e boas condições de trabalho. Nessa perspectiva, podemos entender, então, porque a maioria dos professores da instituição se sentem incapazes diante de desafios como lecionar Ciências e Biologia para alunos com deficiência visual. 


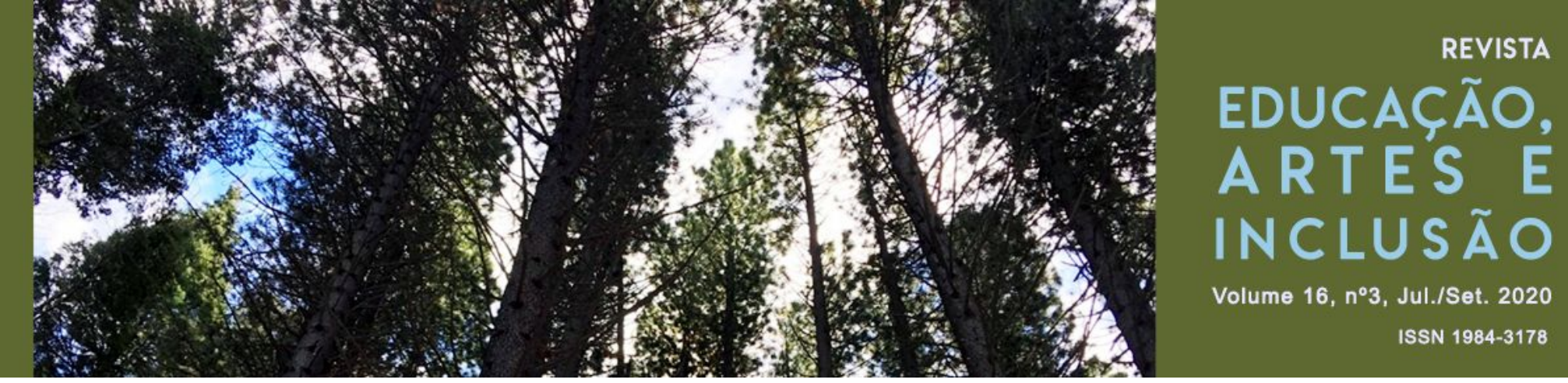

possivelmente, tiveram pouco incentivo à temática Diversidade durante a graduação (DECHICHI; SILVA, 2008).

O processo inclusivo pode ser visto de duas maneiras pelos profissionais docentes: a primeira seria negativa, onde o professor se afasta dos novos conhecimentos acerca da inclusão e não procura, nem vê motivos para sair da sua zona de conforto, com a visão de um ensino estático e inflexível; a segunda é a de sensibilização e busca por novas metodologias e conhecimentos, tendo como motivação o aprendizado do aluno e a busca de conhecimentos como profissional da educação.

A escola, além de ser uma instituição voltada para a educação formal dos alunos, está inserida em um contexto social, no qual os docentes devem ser estimulados constantemente por meio de discussões, palestras, conversas, campanhas, dentre outras formas, para tentar se sensibilizar às questões que rondam o ensino inclusivo. Esses momentos se tornam significativos por serem espaços de apresentação de conhecimentos, esclarecimento de dúvidas, em que os professores podem ter um diálogo aberto com profissionais da área, expor suas inseguranças e possíveis ideias. Ouvir o que os docentes têm a dizer é uma das etapas para a construção de um processo inclusivo, onde os setores da escola como um todo podem identificar os pontos que devem ser melhorados e quais ações devem ser reforçadas para um ensino inclusivo.

\section{CONSIDERAÇÕES FINAIS}

Os dados obtidos através da pesquisa evidenciaram resultados expressivos e relevantes sobre os fatores que rondam a prática docente de professores de Ciências e Biologia em um ensino que busca ser inclusivo. Podemos observar que, apesar de toda estrutura e materiais adaptados aos alunos com deficiência presentes na instituição, os docentes do Colun ainda possuem barreiras que 


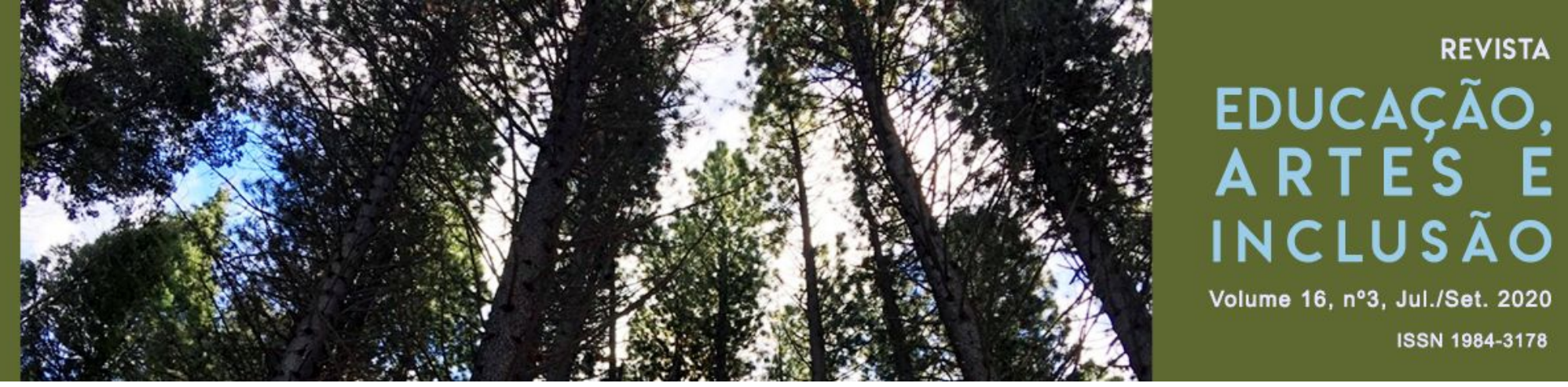

perpassam desde conhecimento teórico até atitudinais, algumas devido a certa negligência na formação inicial desses profissionais, como a falta de disciplinas que abordassem os conteúdos específicos de Ciências relacionados à diversidade, bem como a falta de experiências significativas no Estágio, que poderia representar um momento de propor novas abordagens que sensibilizassem os licenciandos enquanto futuros professores.

Alguns fatores específicos das disciplinas de Ciências e Biologia são a sua natureza visual, os seus conteúdos abstratos, e que geralmente são abordados com o auxílio de imagens. A abordagem desses conteúdos precisa levar em consideração a substituição dessa ênfase no aspecto visual por metodologias que alcancem os alunos com deficiência visual, seja fazendo uso de materiais que estimulem o tato ou a audição. Dentro de um ensino que pretende ser inclusivo, os professores são peças-chave, pois convivem diariamente com os alunos. Nesse contexto, o fato de muitos não se sentirem capazes e preparados para lidar com a diversidade, pode interferir no processo de ensino e aprendizagem.

Em linhas gerais, para que uma prática docente seja voltada às questões da diversidade, além da atenção durante a formação inicial, o incentivo à formação continuada também tem seu valor. Dessa maneira, nas instituições de ensino deve haver o estímulo à participação em cursos, palestras, oficinas e discussões que auxiliem o professor em sua metodologia, seja em suas atividades em sala de aula ou em seus momentos de planejamento.

\section{REFERÊNCIAS}

ALVES, I. K. A formação docente no contexto da Educação Inclusiva. 2012. Monografia (Especialização em Educação Especial e Processos Inclusivos) - Universidade Federal do Rio Grande do Sul, Porto Alegre, 2012.

BOGDAN, R; BIKLEN, S. Investigação qualitativa em Educação: fundamentos, métodos e técnicas. In: Investigação qualitativa em Educação. Portugal: Porto Editora, 1994. p. 15-80. 


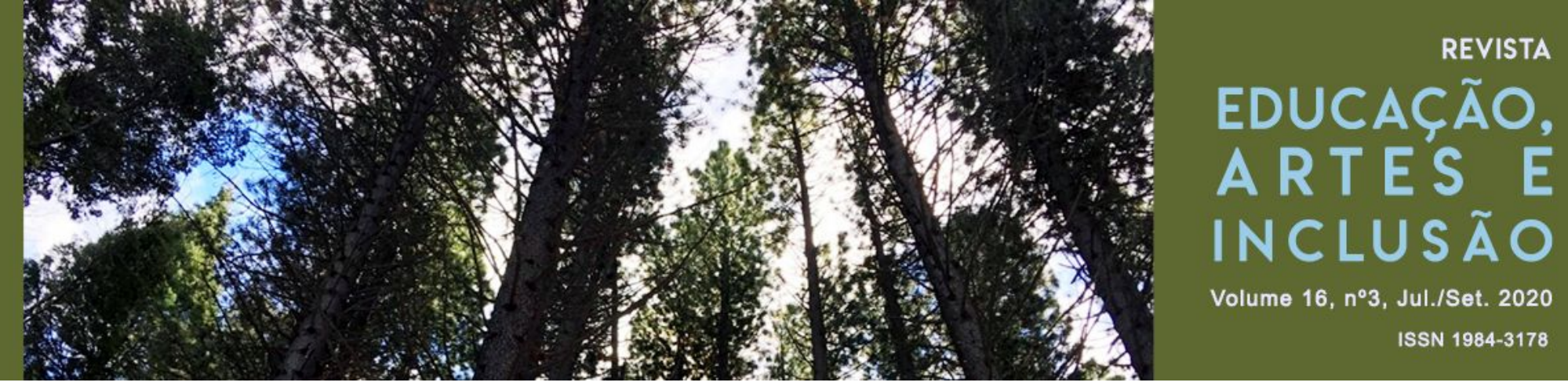

BRASIL. Declaração de Salamanca: sobre princípios, políticas e práticas na área das necessidades educativas especiais. Brasília: MEC, 1994.

BRASIL. Lei de Diretrizes e B. Lei n 9.394/96, de 20 de dezembro de 1996. Brasília: Senado Federal, 1996.

BRASIL. Diretrizes Nacionais para a Educação Especial na Educação Básica. Brasília: MEC, 2001a.

BRASIL. Diretrizes Curriculares Nacionais para a Formação de Professores da Educação Básica. Brasília: MEC, 2001b.

BRASIL. Resolução CNE/CEB Nº 2, de 11 de setembro de 2001. Brasília: MEC, 2001C.

BRASIL. Política Nacional de Educação Especial na Perspectiva da Educação Inclusiva. Brasília: MEC, 2008.

BRASIL. Tecnologia Assistiva. Brasília: CORDE, 2009.

BRAUN, P; MARIN, M. Práticas docentes em tempos de inclusão: uma experiência na escola básica. Revista e-Mosaicos, Rio de Janeiro, v. 1, n.2, p. 3-12, 2012.

CAPELLINI, V; RODRIGUES, O. Concepção de professores acerca dos fatores que dificultam o processo de inclusão. Revista Educação, Porto Alegre, v. 32, n. 3, p. 355-364, 2009.

CARVALHO, R. E. Educação Inclusiva: com os pingos nos "is". Porto Alegre: Mediação, 2014.

CASTRO, J. A. Evolução e desigualdade na educação brasileira. Educação e Sociedade, Campinas, vol. 30, n. 108, p. 673-697, out. 2009.

CORREAA, D. L. A educação inclusiva no ensino de Biologia em uma escola de aplicação, em São Luís - MA: concepções, trabalhos desenvolvidos e contribuições. 2015. Monografia (Graduação em Ciências Biológicas) - Universidade Federal do Maranhão, São Luís, 2015.

COSTA, A. P. A importância da afetividade escolar no processo de inclusão social. 2011. Monografia (Especialização em Desenvolvimento Humano) - Universidade de Brasília, Brasília, 2011.

CUNHA, A. M. S. Educação profissional e inclusão de alunos com deficiência: um estudo no Colégio Universitário/UFMA. 2011. Dissertação (Mestrado em Educação) Universidade Federal do Maranhão, São Luís, 2011. 


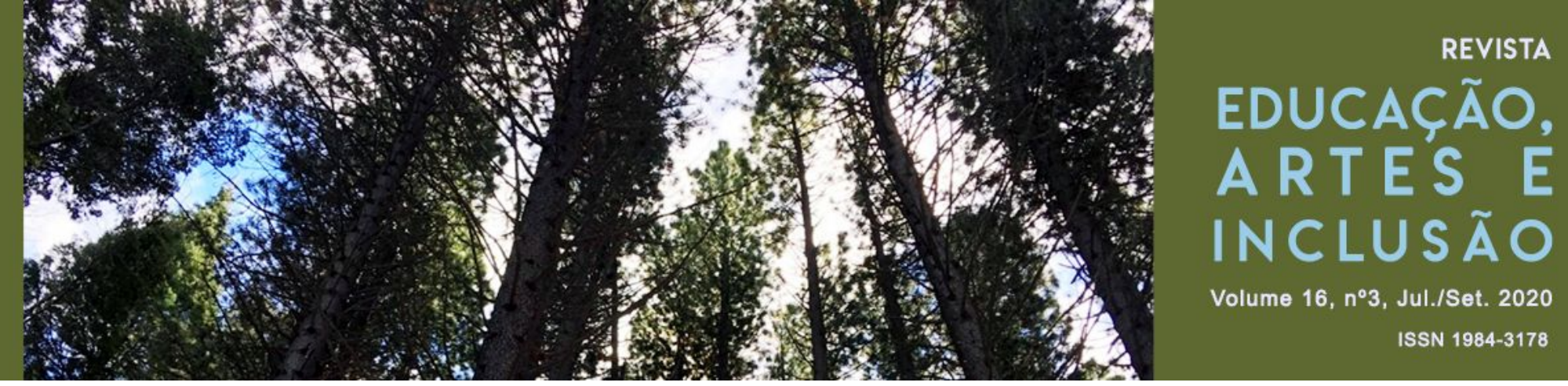

DECHICHI, C; SILVA, L. C. Inclusão Escolar e Educação Especial: teoria e prática na diversidade. Uberlândia: EDUFU, 2008.

DUEK, V. P. Professores diante da Inclusão: superando desafios. In: IV Congresso Brasileiro de Multidisciplinar de Educação Especial, 4., 2007. Anais [...]. Londrina, 2007. p. 1-8.

GIL, M. (org.). Deficiência Visual. Brasília: MEC, 2000.

GIROTO, C. R. M; POKER, R. B; OMOTE, S. (org.). As tecnologias nas práticas pedagógicas inclusivas. São Paulo: Cultura Acadêmica, 2012.

GLAT, R; PLETSCH, M. D; FONTES, R. S. Educação Inclusiva \& Educação Especial: propostas que se complementam no contexto da escola aberta à diversidade. Revista Educação, Santa Maria, v. 32, n. 2, p. 343-356, 2007.

JESUS, D. M; EFFGEN; A. P. S. Formação docente e práticas pedagógicas: conexões, possibilidades e tensões. In: MIRANDA, T. G.; FILHO, T. A. G. (org.). O professor e a educação inclusiva: formação, práticas e lugares. Salvador: EDUFBA, 2012. p. 17-24.

KLIEME, E; VIELUF, S. Teaching practices, teachers' beliefs and attitudes. In: Creating effective teaching and learning environments: first results from TALIS. Paris: COED, 2009. p. 87-135.

LIPPE, E. M. O; CAMARGO, E. P. O ensino de Ciências e deficiência visual: uma investigação das percepções da professora de Ciências com relação à inclusão. In: Jornada de Educação Especial, 10., 2010, São Paulo. Anais [...]. São Paulo, 2010. p. 1-7.

MANTOAN, M. T. E. Inclusão Escolar: O que é? Por que? Como fazer?. São Paulo: Moderna, 2003.

MORAES, R; GALIAZZI, M. Análise textual discursiva. ljuí: Editora Unijuí, 2016.

MORAES, R. Uma tempestade de luz: a compreensão possibilitada pela análise textual discursiva. Ciência \& Educação, Bauru, v. 9, n. 2, p. 191-210, 2003.

NÓVOA, A. Formação de professores e formação docente. Lisboa: Dom Quixote, 1992.

PLETSCH, M. D. A formação de professores para a educação inclusiva: legislação, diretrizes políticas e resultados de pesquisas. Revista Educar, Curitiba, n. 33, p. 143-156, 2009.

PORTAL INEP. Censo Escolar 2014: Sinopses Estatísticas da Educação Básica. Disponível em: http://portal.inep.gov.br/web/guest/sinopses-estatisticas-da-educacao-basica. Acesso em: 22 mar. 2018. 


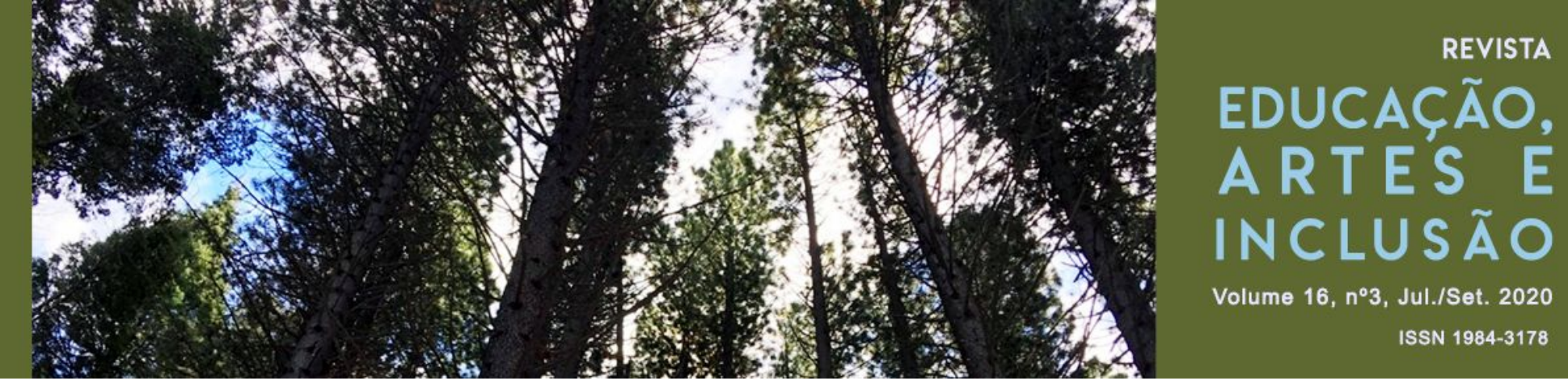

RIVAS, N. P. P; PEDROSO, C. C. A. P; LEAL, M. A. I; CAPELINI, H. A. A (re)significação do trabalho docente no espaço escolar: currículo e formação. In: Congresso Estadual Paulista sobre Formação de Educadores, 8., 2005, São Paulo. Anais [...]. São Paulo, 2005. p. 6-13.

SANT'ANA, I. M. Educação Inclusiva: concepções de professores e diretores. Psicologia em Estudo, Maringá, v. 10, n. 2, p. 227-234, 2005.

SEEGGER, V; CANES, S. E; GARCIA, C. A. X. Estratégias Tecnológicas na Prática Pedagógica. Monografias Ambientais, Santa Maria, v. 8, n. 8, p. 1887-1899, 2012.

SILVA, T. V. Inclusão Escolar: relação família-escola. In: Congresso Nacional de Educação, 12., 2015, Curitiba. Anais [...]. Curitiba, 2015. p. 14243 - 14254.

TEODORO, N. C. Materiais didáticos de ciências e biologia para alunos com necessidades educacionais especiais. Revista da SBEnBio, v.1, n. 7, p. 6173-6184, 2014.

TOLEDO, E. H; MARTINS, J. B. A atuação do professor diante do processo de inclusão e as contribuições de Vygotsky. In: Congresso Nacional de Educação, 9., 2009, Curitiba. Anais [...]. Curitiba, 2009. p. 4127-4138.

WEIGERT, C. Exclusão/Inclusão na escola: fronteiras que (de)limitam olhares. 2017. Tese (Doutorado em Educação) - Universidade Estadual de Campinas, Campinas, 2017.

YIN, R. K. Estudo de Caso: planejamento e métodos. Porto Alegre: Bookman, 2001.

Recebido em 20/06/2019 Aprovado em 30/06/2020 